\title{
Correction to: Aluminum Production in the Times of Climate Change: The Global Challenge to Reduce the Carbon Footprint and Prevent Carbon Leakage
}

\author{
GUDRUN SAEVARSDOTTIR $\mathbb{1 0},{ }^{1,5}$ HALVOR KVANDE ${ }^{2}$ and \\ BARRY J. WELCH ${ }^{3,4}$
}

1.-Department of Engineering, Reykjavik University, 101 Reykjavik, Iceland. 2.-The Norwegian University of Science and Technology, Trondheim, Norway. 3.-University of New South Wales, Sydney, Australia. 4.-Welbank Consulting Ltd, Whitianga, New Zealand. 5.-e-mail: gudrunsa@ru.is

CORRECTION TO: JOM, VOL. 72, NO. 1, 2020

https://doi.org/10.1007/s11837-019-03918-6

The authors note that Fig. 2 is incorrect in the original publication of this article. The correct Fig. 2 appears here.

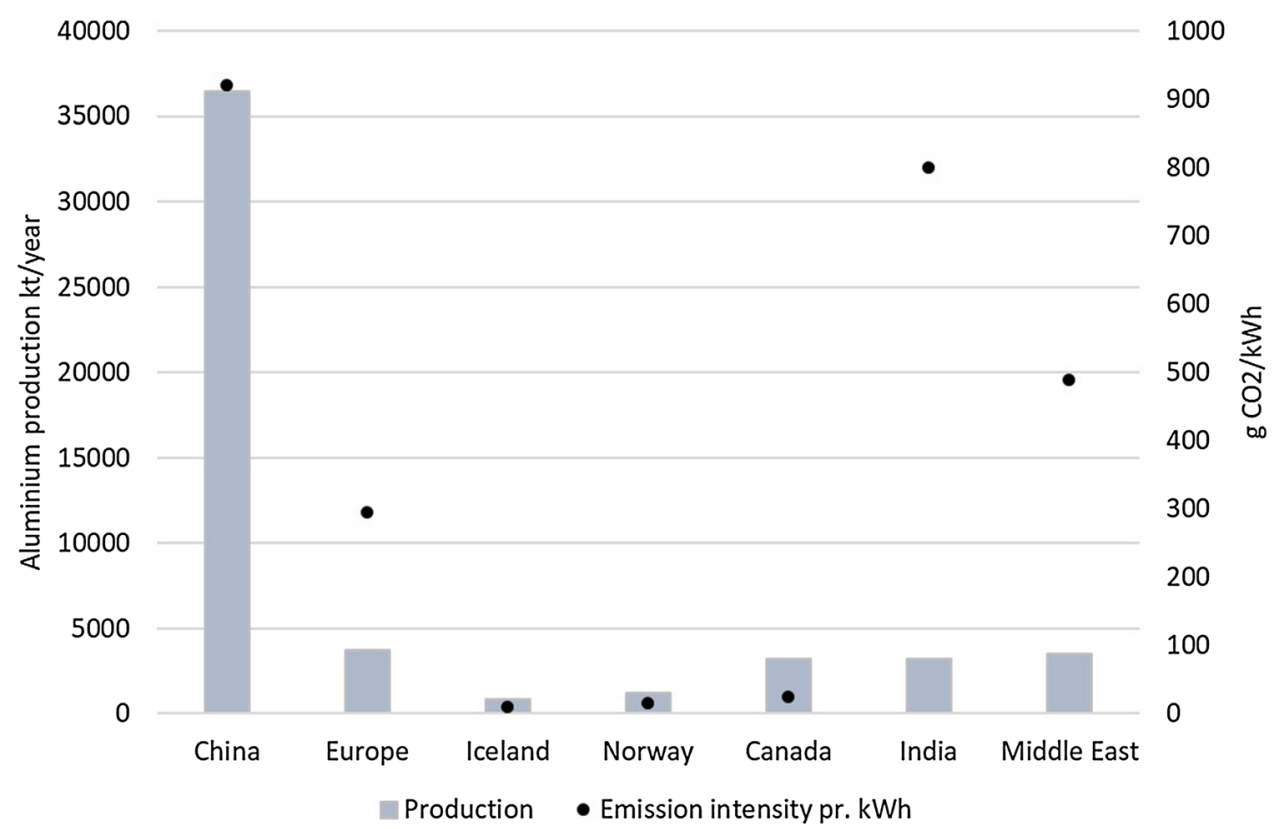

Fig. 2. The aluminum production given in $\mathrm{kt} /$ year and the corresponding average $\mathrm{CO}_{2}$ emission intensity given in $\mathrm{gCO} \mathrm{C}_{2} \mathrm{e} / \mathrm{kWh}$ for different aluminum-producing countries [1, 5, 6, 14-19].

Publisher's Note Springer Nature remains neutral with regard to jurisdictional claims in published maps and institutional affiliations. 